\title{
ESOPHAGEAL MOBILIZATION IN THE TREATMENT OF SHORT ESOPHAGUS
}

\author{
Dragan Canovic $^{1,2}$, Bojan Milosevic ${ }^{1,2}$, Dejan Lazic ${ }^{1,2}$, Aleksandar Cvetkovic ${ }^{1,2}$, Marko Spasic ${ }^{1,2}$, Bojan Stojanovic ${ }^{1,2}$, \\ Slobodanka Mitrovic ${ }^{2,3}$, Mladen Pavlovic ${ }^{1,2}$ \\ ${ }^{1}$ Clinic for General and Thoracic surgery, Clinical center Kragujevac, Kragujevac, Serbia \\ ${ }^{2}$ Faculty of Medical Sciences, University of Kragujevac, Kragujevac, Serbia \\ ${ }^{3}$ Department for pathologic and anatomic diagnostics, Clinical center Kragujevac, Kragujevac, Serbia

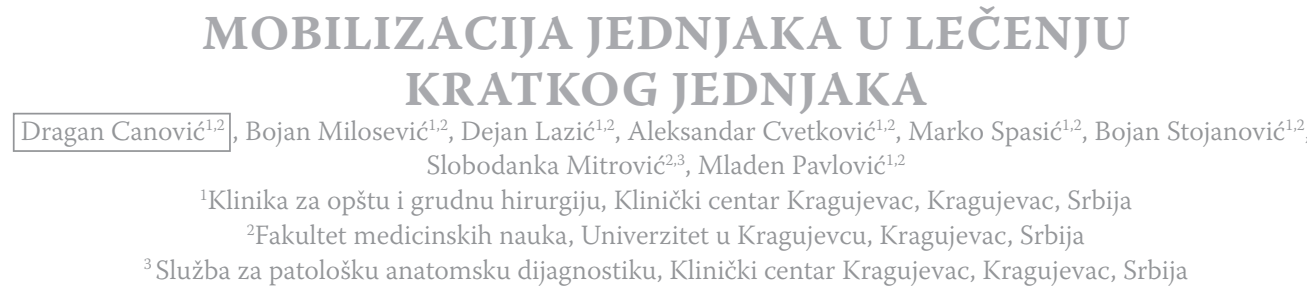

Received / Primljen: 15. 10. 2016.

\begin{abstract}
Short esophagus is well known complication of a long term gastroesophageal disease. There are several ways to solve this problem intraoperatively. One of the first steps is extensive esophageal mobilisation. In this review we emphasize different approaches and types of this procedure, with their advantages and disadvantages.
\end{abstract}

Keywords: Esophagus, short; frenotomy; vagotomy

\section{SAŽETAK}

Sindrom kratkog jednjaka je dobro poznata komplikacija dugotrajne gastroezofagealne refluksne bolesti. Postoji nekoliko načina za rešavanje ovog problema intraoperativno. Jedan od prvih koraka je ekstenzivna mobilizacija jednjaka. U ovom radu dajemo pregled različitih pristupa $i$ vrsta ove procedure, sa svojim prednostima i manama.

Ključne reči: Kratak jednjak; frenotomija; vagotomija

\section{INTRODUCTION}

The short esophagus (SE) is a recognized complication of long-standing gastroesophageal reflux disease (GERD) wherein the gastroesophageal junction (GEJ) cannot be sufficiently reduced below the crura of the diaphragm (1). For many years this syndrome creates controversy among surgeons. Although some even claim that this entity does not exist, there are many esophageal surgeons who agree that long-term reflux disease, scarring and axial contraction of the longitudinal muscle layer of the esophagus leads to its shortening $(2,3)$. The only way to confirm the presence of a short esophagus is intraoperative inability to maintain the gastroesophageal junction below the diaphragm without significant tension (4-7). A fundoplication performed around an intrinsically short esophagus without a lengthening procedure will have a high failure rate because of mediastinal wrap herniation or disruption due to excessive tension. This is believed to be responsible for approximately $20-35 \%$ of the surgical failures after open or laparoscopic antireflux surgery (8-10). In the era of laparoscopic antireflux surgery it is imperative to identify the short esophagus preoperatively. Although many of diagnostic procedures were used to assess abdominal esophageal length preop- eratively, no one had a significant sensitivity and specificity. Some risk factors were used earlier as preopearative predictors of this syndrome, with low sensitivity and specificity, such as irreducible hiatus hernia greater than $5 \mathrm{~cm}$, paraesophageal hernia, stricture/fibrosis, Barrett`s esophagus and short manometric length $(3,4,6)$. Yano et al established esophageal length index (ELI) and endoscopic esophageal length (EEL) as a valuable additional predictors of short esophagus $(11,12)$. These parameters had significantly higher sensitivity and specificity for this final stage of GERD.

Key part in reflux disease treating is successfully launching esophagogastric junction below the diaphragm with a minimum tension, for at least $2.5 \mathrm{~cm}$ below the esophageal hiatus, which is the acceptable length that guarantees antireflux valve positioning in the abdomen and its functioning $(8,13)$. The most common diseases in which mobilization of the esophagus is carried out, near the syndrome of the short esophagus, are malignant diseases of the esophagogastric junction and corrosive damage to the esophagus. Achieving a technically satisfactory reconstruction of the cardia by way of an antireflux procedure is substantially more difficult under these conditions. Even when a good 
repair may be achieved, its durability may be compromised by the continued cephalad tension on the gastroesophageal junction, which may lead to recurrent herniation. Surgicaly lengthening of the short esophagus can be achieved in several ways. First is extensive mediastinal mobilization and division of the esophagus from the mediastinal structures. Second, when this method is not enough, is to perform a Collis gastroplasty. Third and somewhat extreme solution is to perform an esophageal resection. There are several approaches to perform mediastinal mobilization for obtaining adequate esophageal length. In this paper we review these methods.

\section{Types of mobilization}

There are two main types of esophageal mobilization (14). Type 1 is standard for fundoplication, and consists of complete dissection and exposure of diaphragmatic pillars, specially of the right pillar, by means of the opening of the hepatoduodenal and hepatogastric ligaments, side by side with the release of the gastric end of the diaphragm $(15,16)$. At this step, care is taken to preserve the hepatic branch of the vagus nerve. Also, the peritoneum and the phrenoesophageal membrane should be lifted, thus mobilizing the esophagus in the posterior mediastinum and keeping the baseline morphology of the esophageal hiatus. Type 2 implies transhiatal large mediastinal dissection, with separation of the esophageal body from surrounding mediastinal structures (14).

\section{Procedure approaches}

Two approaches that most common have been used for the mobilization of the esophagus are transabdominal and transthoracic. Within them are considered laparotomy and thoracotomy, and lately laparoscopic and thoracoscopic approach. These approaches are the subject of many studies that seek to determine whether there is an advantage over others in terms of providing an adequate length of intra-abdominal part of the esophagus with minimal post-operative complications $(14,17)$. As an alternative method mentioned Collis gastroplasty which can be performed via laparotomy and by laparoscopy. This technique consists in increasing the length of the abdominal part of the esophagus through gastroplasty conducted in parallel with the axis of the esophagus (18-20). This method has been criticized because of the presence of parietal cells that secrete gastric acid in neoesophagus and because of reduced motility that allows direct contact between the acidic contents and mucosa of the esophagus $(1,11,19)$. Despite this gastroplasty and fundoplication can be effective in controlling symptoms of the reflux $(10,17)$. Traditionally, in patients with suspected syndrome of short esophagus is conducted transthoracic fundoplication because this approach provides ideal conditions for the mobilization of the esophagus and allows Collis gastroplasty when it is needed.

\section{Frenotomy}

Laparotomy approach gives good results, although it has been shown that a wide frenotomy can be very important in the implementation of mediastinal dissection, which increases the length of the abdominal part of the esophagus for about $1 \mathrm{~cm}$ as compared to patients who never opened diaphragm (the average length of the esophagus obtained during frenotomy is $3.24 \mathrm{~cm}$ compared to $2.12 \mathrm{~cm}$ in patients with laparotomy only) $(14,21)$. These results indicate that frenotomy, although it is not a routine procedure, can be an alternative approach when, during laparotomy approach, is established that antireflux valve is not able to stay in the abdomen.

\section{Vagotomy}

Left anterolateral thoracotomy is approach through which is possible to do a dissection of the esophagus and afterwards anterior and posterior vagotomy (the length of the esophagus, which is obtained after anterior vagotomy is approximately 1.12 centimeters while after the posterior vagotomy is about $0.97 \mathrm{~cm}$ ). In this way the length of the esophagus from about $3.81 \mathrm{~cm}$ can be achieved, which is significantly more than by laparotomy (21). Lately described a new technique of vagus nerve division that should make a greater length of the esophagus. It consists in the dissection of the both vagus nerves at three levels, resulting in an increase of the length of the abdominal esophagus $(3.7 \mathrm{~cm} \pm 1.2 \mathrm{~cm})(22)$. The key technical moments are blunt distal esophagus preparation of its intrathoracic attachment which includes regional lymphatics of the lower mediastinum and multiple vagal transections at several levels. Number of vagus nerve transections (three) is necessary because, after transection at each level about $1 \mathrm{~cm}$ lengthening of the esophagus is achieved. The final length represents the additive effect of the individual transections. Although the complete dissociation of the esophagus from the nerves is technically feasible, it should be avoided because of the risk of extensive laceration of muscular layer and even perforation. This approach is not entirely accepted among surgeons. In a certain number of patients who are operated for peptic ulcer occurs the disorder in the motility of the stomach, which often require additional drainage procedure. Role of this procedure in the treatment of short esophagus was examined in a prospective study and it was found that does not lead to increased rates of delayed gastric emptying nor other possible effects (21).

\section{Laparoscopy approach}

Introduction of laparoscopic antireflux surgery and the development of techniques that allow laparoscopic mediastinal mobilization of the esophagus, raise the question whether it is possible to get a similar length of the esophagus with less invasive laparoscopic approach. 
In this regard conducted experimental studies on animals (pigs) where laparoscopic and thoracoscopic mobilization have been done, as well as mobilization with or without bilateral section of the vagus nerve. Laparoscopic mobilization average increase in length of the esophagus was only $4 \mathrm{~mm}$, which is significantly less than the average increase in length of $12 \mathrm{~mm}$ with transthoracic esophageal mobilization. The average length of next $6 \mathrm{~mm}$ was obtained with transthoracic access after laparoscopic mobilization (23). Further increasing the length of the esophagus was obtained with section of the vagus nerves, but there were no a significant difference of the length with division of the anterior in relation to the posterior vagus nerve obtained. The maximum mobilization of the esophagus, an average of $18.5 \mathrm{~mm}$ was obtained by a complete esophageal mobilization and bilateral section of vagi. It is shown that transthoracic mobilization leads to a significant increase in the length of the esophagus compared to laparoscopic mobilization (24). Laparoscopic visualization of the esophagus in the lower mediastinum is an excellent but the dissection of the esophagus below the lung hilum does not provide a large increase in the length of the esophagus. It was established that during transthoracic mobilization part of laparoscopic dissection who did not satisfactorily done is the preparation of the bronchial arteries and branches of the vagus to the hilus, especially in main bronchi. It would be possible to implement a similar preparation laparoscopically but work high in the mediastinum, near the pulmonary artery and bronchial blood vessels is a difficult and potentially dangerous (25). Although, minimal mobilization of the esophagus during laparoscopic fundoplication reduces postoperative migration and the need for the reoperation. It was established that dissection of the vagus nerve without esophageal mobilization significantly increases the length of the esophagus (21). However the maximum length of the esophagus can be achieved by a combination of mediastinal mobilization and vagotomy. Even when the main vagus is dissected, small branches to the lung hilus make difficult to obtain the desired length of the esophagus. Section of small branches of the vagus does not eliminate the fixating role of this nerve. This indicates that in the case of mobilization of the esophagus itself is not sufficient to ensure the maintenance of esophagogastric junction below the diaphragm, one should take into account the vagus dissection $(26,27)$. Unilateral vagal injuries is relatively common, especially in antireflux surgery procedures, and usually are well tolerated. Transection of both major vagus branches will give an even greater increase in the length of the esophagus, but morbidity due to bilateral truncal vagotomy can be greater than the benefits of additional length of the esophagus, especially when you take into account the possibility of Collis gastroplasty $(21,28)$. Due to the short length of the esophagus which is obtained by unilateral vagotomy this technique should not be used as a replacement for the mobilization of the esophagus. Extensive esophageal mobilization alone should be used as the primary method to increase the esophageal length. Since thoracotomy can be a significant cause of respiratory complications, endoscopic methods for mobilization, resection and reconstruction of the esophagus have been widely used. During thoracoscopic mobilization right lung deflation is done, and in about one-quarter of patients is necessary to apply antibiotic treatment for respiratory problems. A small number of previous studies have shown that there is no advantage of the thoracoscopic mobilization compared to the open approach, but some studies showed that the thoracoscopic approach does have a larger number of complications compared to traditional, open technique, although in this study mobilization of the esophagus as a component part of esophagectomy was examined $(14,25,29,30)$. Based on previous studies it was shown that the maximum length of the abdominal part of the esophagus was obtained using thoracic approach (3). However, given that in this approach bilateral vagotomy is a condition for obtaining the maximum length of the esophagus, which carries a certain morbidity and postoperative complications, laparotomy approach should be used and Collis gastroplasty if necessary.

\section{CONCLUSION}

This common problem of short esophagus requires high volume centers and experienced surgeons to solve. There are several approaches to establish enough abdominal esophageal length, and they depend on type of the disease that caused axial esophageal shortening. Esophageal mobilization is often enough to achieve enough esophageal length, either performed through thoracic or laparotomy approach. Frenotomy or vagotomy, in combination with minimally invasive approaches, can be additional maneuvers that help to avoid gastroplasty procedures.

\section{REFERENCES}

1. Nason KS, Luketich JD, Awais O, Abbas G, Pennathur A, Landreneau RJ, et al. Quality of life after collis gastroplasty for short esophagus in patients with paraesophageal hernia. Ann Thorac Surg. 2011 Nov;92(5):1851-4.

2. Mattioli S, Lugaresi ML. Lengthening Gastroplasty for Managing Gastroesophageal Reflux Disease and Stricture. In: Ferguson MK, editor. Difficult Decisions in Thoracic Surgery: An Evidence-Based Approach. London: Springer London; 2007. p. 305-17.

3. Teitelbaum EN, Soper NJ. The Short Esophagus. In: Swanstrom LL, Dunst MC, editors. Antireflux Surgery. New York, NY: Springer New York; 2015. p. 177-87.

4. Gastal OL, Hagen JA, Peters JH, Campos GM, Hashemi M, Theisen J, et al. Short esophagus: analysis of predictors and clinical implications. Arch Surg. 1999 Jun;134(6):633-8. 
5. Bochkarev V, Lee YK, Vitamvas M, Oleynikov D. Short esophagus: how much length can we get? Surg Endosc. 2008 Oct;22(10):2123-7.

6. Low DE. The short esophagus recognition and management. J Gastrointest Surg. 2001;5(5):458-61.

7. Herbella FAM, Del Grande JC, Colleoni R. Short esophagus: literature incidence. Dis Esophagus. 2002;15(2):125-31.

8. Jobe BA, Richter JE, Hoppo T, Peters JH, Bell R, Dengler WC, et al. Preoperative Diagnostic Workup before Antireflux Surgery: An Evidence and Experience-Based Consensus of the Esophageal Diagnostic Advisory Panel. J Am Coll Surg. 2016 Sep 18;217(4):586-97.

9. Horvath KD, Swanstrom LL, Jobe BA. The short esophagus: pathophysiology, incidence, presentation, and treatment in the era of laparoscopic antireflux surgery. Ann Surg. 2000 Nov;232(5):630-40.

10. Zehetner J, DeMeester SR, Ayazi S, Kilday P, Alicuben ET, DeMeester TR. Laparoscopic Wedge Fundectomy for Collis Gastroplasty Creation in Patients With a Foreshortened Esophagus. Ann Surg. 2014;260(6).

11. Garg N, Yano F, Filipi CJ, Mittal SK. Long-term symptomatic outcomes after Collis gastroplasty with fundoplication. Dis Esophagus. 2009;22(6):532-8.

12. Yano F, Stadlhuber RJ, Tsuboi K, Garg N, Filipi CJ, Mittal SK. Preoperative predictability of the short esophagus: endoscopic criteria. Surg Endosc. 2009 Jun;23(6):1308-12.

13. Herbella FAM, Del Grande JC, Colleoni R. Short esophagus or bad dissected esophagus? An experimental cadaveric study. J Gastrointest Surg. 2003;7(6):721-5.

14. Beduschi T, Bigolin AV, Cavazzola LT. Thoracotomy versus transhiatal esophageal dissection: which is the best surgical approach to short esophagus? Acta Cir Bras. 2011;26(3):214-9.

15. St. Peter SD, Barnhart DC, Ostlie DJ, Tsao K, Leys CM, Sharp SW, et al. Minimal vs extensive esophageal mobilization during laparoscopic fundoplication: A prospective randomized trial. J Pediatr Surg. 2011;46(1):163-7.

16. Lee JW, Sung SW, Park JK, Park CH, Song KY. Laparoscopic gastric tube formation with pyloromyotomy for reconstruction in patients with esophageal cancer. Ann Surg Treat Res. 2015;89(3):117-23.

17. Durand L, De Anton R, Caracoche M, Covian E, Gimenez M, Ferraina P, et al. Short esophagus: selection of patients for surgery and long-term results. Surg Endosc. 2012 Mar;26(3):704-13.

18. Alaeddine MH, Safadi BY. Laparoscopic Collis Gastroplasty and Nissen Fundoplication. In: Hoballah JJ, Scott-Conner MD HCE, editors. Operative Dictations in General and Vascular Surgery. New York, NY: Springer New York; 2012. p. 50-4.
19. Mor A, Lutfi R, Torquati A. Esophageal acid-clearance physiology is altered after Nissen-Collis gastroplasty. Surg Endosc. 2013 Apr;27(4):1334-8.

20. Pera M, Deschamps C, Taillefer R, Duranceau A. Uncut Collis-Nissen gastroplasty: early functional results. Ann Thorac Surg. 1995 Oct;60(4):915-20; discussion 921.

21. Oelschlager BK, Yamamoto K, Woltman T, Pellegrini C. Vagotomy during hiatal hernia repair: A benign esophageal lengthening procedure. J Gastrointest Surg. 2008;12(7):1155-62.

22. Arkadopoulos N, Marinis A, Dafnios N, Theodosopoulos T, Smyrniotis V. A novel technique for gaining extra length of the abdominal esophagus. Am J Surg. 2009 Jul;198(1):e10-2.

23. Smithers BM, Gotley DC, McEwan D, Martin I, Bessell J, Doyle L. Thoracoscopic mobilization of the esophagus. Surg Endosc. 2001;15(2):176-82.

24. Worrell SG, Boys JA, DeMeester SR. Identification and Management of a "Short Esophagus" and a Complex Hiatus. In: Aye WR, Hunter GJ, editors. Fundoplication Surgery: A Clinical Guide to Optimizing Results. Cham: Springer International Publishing; 2016. p. $31-7$.

25. Ma Z, Niu H, Gong T. Thoracoscopic and laparoscopic radical esophagectomy with lateral-prone position. J Thorac Dis. 2014;6(2):156-60.

26. Tsuboi K, Omura N, Yano F, Hoshino M, Yamamoto SR, Akimoto S, et al. A novel laparoscopic approach for severe esophageal stenosis due to reflux esophagitis: how to do it. Surg Today. 2015 Feb;45(2):253-7.

27. Yau P, Watson DI, Jamieson GG, Myers J, Ascott N. The influence of esophageal length on outcomes after laparoscopic fundoplication. J Am Coll Surg. 2000 Oct;191(4):360-5.

28. Oelschlager B, Yamamoto K, Woltman T, Pellegrini C. Re: Oelschlager BK, Yamamoto K, Woltman T, Pellegrini C. Vagotomy during hiatal hernia repair: A benign esophageal lengthening procedure. J Gastrointest Surg. 2008;12(7):1155-62. J Gastrointest Surg. 2009;13(2):395.

29. Mattioli S. Difficult Decisions in Thoracic Surgery. Ferguson K M, editor. 2007.

30. Zilberstein B, Cecconello I, Pollara W, Domene CE, Nasi A, Pinotti HW. Esophagectomy Without Thoracotomy Using the Cervicoabdominal Approach for the Management of Esophageal Carcinoma: Results. In: Siewert JR, Hölscher AH, editors. Diseases of the Esophagus. Berlin, Heidelberg: Springer Berlin Heidelberg; 1988. p. 398-402. 